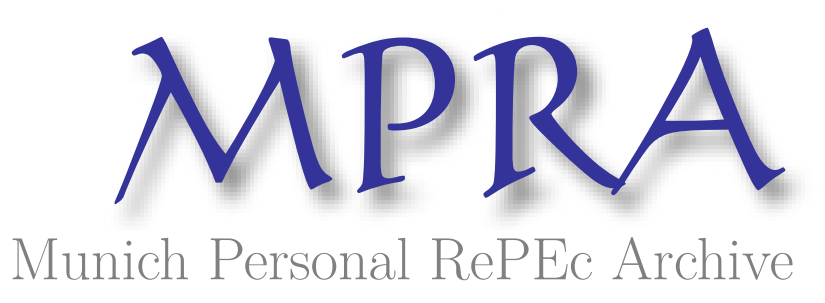

\title{
Option Implied Risk-Neutral Distributions and Implied Binomial Trees: A Literature Review
}

\author{
Jackwerth, Jens Carsten
}

Universität Konstanz

1999

Online at https://mpra.ub.uni-muenchen.de/11634/

MPRA Paper No. 11634, posted 20 Nov 2008 01:21 UTC 


\title{
Option Implied Risk-Neutral Distributions and
}

\section{Implied Binomial Trees:}

\section{A Literature Review}

\author{
Jens Carsten Jackwerth*
}

First draft: May 4, 1999

This version: September 26, 1999

D:|Research\Paper14\Paper2 double.doc

\begin{abstract}
In this partial and selective literature review of option implied risk-neutral distributions and of implied binomial trees, we start by observing that in efficient markets, there is information contained in option prices, which might help us to design option pricing models. To this end, we review the numerous methods of recovering risk-neutral probability distributions from option prices at one particular time-to-expiration and their applications. Next, we extend our attention beyond one time-to-expiration to the construction of implied binomial trees, which model the stochastic process of the underlying asset. Finally, we describe extensions of implied binomial trees, which incorporate stochastic volatility, as well as other non-parametric methods.
\end{abstract}

Jens Carsten Jackwerth is an assistant professor at the University of Wisconsin, Madison. For helpful discussions I would like to thank Mark Rubinstein and the editor, Stephen Figlewski. Contact: Department of Finance, School of Business, University of Wisconsin at Madison, 975 University Ave, Room 5279, Madison, WI 53706, (608) 2631797 office, (608) 265-4195 fax, jjackwerth@bus.wisc.edu, http://instruction.bus.wisc.edu/jjackwerth/ 


\section{Option Implied Risk-Neutral Distributions and}

\section{Implied Binomial Trees:}

\section{A Literature Review}

For a long time, option pricing has been conducted in a rather systematic way. First, one makes an assumption about the data-generating process. That is, one assumes a particular stochastic process, which drives the underlying asset price. The most common choice here is the assumption of geometric Brownian motion for the asset price, which was first advocated by Osborne [1959]. Second, one rewrites that process in risk-neutral terms either using arguments about dynamic replication or considering the influence of the price of risk explicitly. Third, the parameters of the model are estimated and finally, fourth, the option is priced.

This systematic way has been sidestepped in only a few cases, most notably concerning the volatility parameter of the Black-Scholes formula. Volatility is the only parameter in the Black-Scholes formula, which is not directly observable. Therefore, practitioners started soon to find the implied value of volatility by fitting the Black-Scholes model to the observed option prices. The number of exchange-traded options was small for a long time after their launch in the early 1970s, and thus the opportunity for any widespread fitting of parameters other than volatility was limited.

This situation changed dramatically towards the end of the millennium. While in the early tests of option pricing such as Rubinstein [1985], the Black-Scholes model was more or less supported, the index options in the US can now no longer be priced with the simple BlackScholes formula. Ever since the stock market crash of 1987, the implied volatilities of index options tend to slope downward across strike prices whereas the Black-Scholes model would 
require a flat volatility smile. Unfortunately, this is only the general pattern and there are deviations from the monotonically downward-sloping smile. So can the smile for very low strike prices flatten out at a high plateau, exhibiting a tilde-shaped pattern. Also, for days where we observe very high strike prices the implied volatilities can rise again, exhibiting a u-shaped pattern. Finally, the smile patterns described become more pronounced as the time-to-expiration shortens and the smile becomes flatter as the time-to-expiration lengthens.

Tompkins [1998] finds this same pattern in index options written on the Japanese, German, and British markets. Other markets also exhibit volatility smiles: Toft and Prucyk [1997] find that individual stock options often exhibit more gently downward sloping smiles, and Campa, Chang, and Reider [1998] find that foreign exchange options often exhibit u-shaped smiles. As researchers were trying to find new option pricing models which were able to explain these option prices, some tried to learn more about the stochastic process of the asset from the observed option prices. This was finally possible since we can now find as many as one hundred simultaneously traded options on the S\&P500 index which all differ from each other in strike price and/or time-to-expiration. Given such plentiful data, it is a small step to ask what those options tell us about the risk-neutral stochastic process of the underlying security. Rubinstein [1994], Derman and Kani [1994], and Dupire [1994] have answered this question in a series of papers on a class of models, which Rubinstein [1994] termed implied binomial trees. These implied trees are extensions of the original Cox, Ross, and Rubinstein [1979] binomial trees.

The present paper provides a partial survey of this literature. Section I starts out with the concept of risk-neutral probabilities and shows how to back out these probabilities from a set of option prices with a given time-to-expiration. Section II then extends this concept of the riskneutral probability distribution with a particular time-to-expiration to cover the whole stochastic process of the asset price across all times. Implied binomial trees and their extensions provide 
here a feasible framework. The current frontier in research is reached with implied binomial trees, which incorporate stochastic volatility. In section III we discuss other non-parametric option pricing models. Many of these models can be viewed as alternative approximations of the volatility surface, which do not share the implied tree structure of the asset price nodes but rather use (rectangular) grids in time and asset price. We conclude in section IV.

\section{Risk-Neutral Probabilities}

Before we turn to the discussion of implied binomial trees, it is useful to review the concept of state-contingent prices $\left(\pi_{\mathrm{i}}\right)$. These are the prices of securities, which promise one dollar if a certain state (i) occurs and zero otherwise. The sum of such state-contingent prices across all states has to equal the price of a risk-free bond, which pays off 1 dollar at maturity (T) for sure. Often it is convenient to normalize the state-contingent prices by the inverse of the price of the bond. The resulting risk-neutral probabilities $\left(\mathrm{P}_{\mathrm{i}}\right)$ then sum to one:

$$
P_{i}=r^{T} \pi_{i}
$$

where $r$ is $1+$ the annual yield of the bond. We can then value any security $(C)$ with payoff $\left(\mathrm{X}_{\mathrm{i}}\right)$ at time $\mathrm{T}$ by calculating the expectation under the risk-neutral probabilities:

$$
C=E_{P}[X] / r^{T}
$$

In a complete market there are either as many securities traded as there are states of the world or there are a sufficient number of intermediate trading times so that there are as many dynamically rebalanced portfolios feasible as there are states of the world. In such complete markets, Ross [1976] shows that one can recover the complete risk-neutral probability 
distribution from a set of European option prices. This distribution turns out to be unique and Breeden and Litzenberger [1978] give an exact formula:

$$
\frac{\partial^{2} C}{\partial K^{2}}=\pi_{S=K}
$$

The second derivative of a European call price (C) taken with respect to its strike price $(\mathrm{K})$ is the state contingent price $(\pi)$ of the future asset price ending up at exactly the strike price of the option. In order to recover the risk-neutral probabilities from option prices, we can follow either of three approaches. First, find a candidate risk-neutral distribution and fit the resulting option prices to the observed prices. Second, fit a function of option prices across strike prices through the observed option prices. Then, use Breeden and Litzenberger [1978] to obtain the riskneutral distribution. Third, fit a function of implied volatilities across strike prices through the observed implied volatilities. Next, calculate the function of option prices across strike prices and, finally, obtain the risk-neutral distribution.

The above methods have been applied in numerous forms and each has some general properties, which affect their performance. Concerning the first approach, fitting the risk-neutral distribution is problematic since probability distributions need to follow certain shapes: they tail of to zero for small and large stock prices, the center of the distribution is often hump-shaped, and they need to sum to one. Concerning the second approach, fitting the function of option prices across strike prices is hardly ever attempted since the function takes the value of the ex-dividend stock price at a strike price of zero and approaches a value of zero for very large strike prices. Moreover, the option prices are bounded by no-arbitrage conditions. Concerning the third approach, fitting the function of implied volatilities is numerically the probably best method. In a 
Black-Scholes economy the smile is just a flat line. Also, as long as the smile is not too curved, the corresponding risk-neutral distribution will be well behaved.

However, the exact correspondence of risk-neutral distributions to sets of option prices depends critically on markets being complete. If markets are incomplete then there are states of the world where we cannot replicate the option. This can arise either because of trading restrictions or because there are additional non-traded factors (such as stochastic volatility or jumps). Then, the observed option prices can be supported by a whole set of risk-neutral distributions and not just by one unique distribution. In turn, that means that we can only establish bounds on option prices, but we can no longer determine unique option prices across strike prices. Masson and Perrakis [1997] explore those bounds when there is a jump component present. Bernardo and Ledoit [1999] and Cochrane and Saa-Requejo [1997] present bounds, which are based on limits on the profitability of investments. The ratio of gains to losses is restricted in the first paper and the Sharp ratio (= expected return per unit of volatility) in the latter.

Due to the paucity of option prices, empirical research was limited at the time of these early papers. Banz and Miller [1978] are a notable exception when they show a capital budgeting application of state prices derived from sets of option prices. However, they did not use actual option prices but effectively ended up calculating the required option prices with the BlackScholes formula.

During the 1980s there was a lull in activity, and Longstaff [1990] proposes the earliest method in the modern literature. Similar to Banz and Miller [1978], he derives a histogram of probabilities directly from the option prices by assuming that the probabilities are uniformly distributed between any two neighboring option strike prices. Unfortunately, his scheme turns out 
to be numerically unstable and exhibits negative probabilities unless the number of available options is large. Mayhew [1995] investigates the stability of this method in detail.

At this point we would like to mention two earlier survey articles. Cont [1997] focuses on particular methods for recovering the risk-neutral probability distributions, whereas Bahra [1997] divides his attention evenly between methods and applications. Cont [1997] also provides the basis for a framework for classifying the different methods into expansion, non-parametric, and parametric methods. We will use related but slightly different categories based on the observation that the two basic extensions of the lognormal distribution are to either find a more flexible parametric distribution or to try a non-parametric method.

\section{Parametric Methods}

Parametric methods can be further divided into three groups. First, expansion methods add correction terms to base distributions in order to make them more flexible. Second, generalized distribution methods introduce more flexible distributions with additional parameters compared to the two parameters of the normal or lognormal distributions. Third, mixture methods model mixtures of simple distributions.

Expansion methods are conceptually related to the expansion of a Taylor series about a point of a function. They typically start with a simple (often normal or lognormal) distributions and then add correction terms in order to obtain more flexible shapes of the risk-neutral distribution, which is fitted to the observed option prices. A general concern in the class is that for certain parameter constellations the risk-neutral distributions can take on negative values. Thus, all results have to be checked for violations of the positivity constraint. 
Abadir and Rockinger [1997] use confluent hypergeometric (or Kummer's) functions as a basis for the risk-neutral density and derive the option price function across strike prices in closed-form. Abken, Madan, and Ramamurtie [1996a and b] use four-parameter Hermite polynomials. These polynomials are related to successive derivatives of the normal density function and provide four correction terms to the normal distribution. Using the same polynomials but restricting some of their coefficients, Jondeau and Rockinger [1998a] and Corrado and $\mathrm{Su}$ [1997] restrict their attention to the class of Gram-Charlier expansions. Jondeau and Rockinger [1998a] also provides an algorithm that forces the coefficients, which are based on the moments of the risk-neutral distribution, to lie within the region that guarantees positive probabilities. Brenner and Eom [1997] use Laguerre polynomials, which are corrections to a gamma distribution. As a main benefit, the authors note that the approximated risk-neutral distribution has unbiased moments. Jarrow and Rudd [1982], Corrado and Su [1996], Longstaff [1995], and Rubinstein [1998] use Edgeworth expansions. Here, a base distribution (lognormal, lognormal, normal, and binomial, respectively) is augmented with correction terms which match successively each of the first four cumulants. These cumulants are closely related to the moments of the option-implied distribution. The authors then search for the set of cumulants which gives the best fit between observed option prices and option prices based on the expanded risk-neutral distribution. Potters, Cont, and Bouchaud [1998] use cumulant expansions to add a single correction term to a normal distribution, which adjusts for the kurtosis of the risk-neutral distribution. This is a somewhat atypical choice since most expansions also try to correct at least for skewness that is for the downward sloping pattern in the implied volatilities. They are able to express their correction as an additional quadratic term in the function of implied volatilities across strike prices. 
Generalized distribution methods use more flexible distributions, which tend to have one or two additional parameters compare to the two parameters of the normal and lognormal distributions. Generalized distributions often include different common distributions as limiting cases for particular parameter constellations.

Aparicio and Hodges [1998] use generalized beta functions of the second kind. These four-parameter distributions have been first described by Bookstaber and McDonald [1987] and include the lognormal, gamma, and exponential distributions, several Burr type distributions, and others. Posner and Milevsky [1998] use the Johnson family of densities. Johnson [1949] proposed to translate normal distributions through logarithmic and hyperbolic sine transformations while adding two additional parameters. Sherrick, Garcia, and Tirupattur [1995] use the Burr III distribution on a data set of options on soybean futures. Sherrick, Irwin, and Forster [1992 and 1996] also use the Burr XII distribution on options on S\&P 500 futures. Curiously these three papers co-authored by Sherrick do not mention how they accommodated the early exercise which is possible for American options on futures. It would be incorrect to just ignore the possibility of early exercise and proceed as if the options were European options.

Mixture methods achieve greater flexibility by drawing with different probabilities from several simple distributions, which each have distinct parameterizations. A problem with mixtures is that the number of parameters increases very fast. For example, mixing three lognormal distributions yields 10 parameters. Two parameters are used for each lognormal and two mixing probabilities are added. The third mixing probability is determined by the requirement that the mixing probabilities have to sum to one. However, given that there are often only 10 or 20 observed option prices across different strike prices, the mixture methods can easily overfit the data. Still, mixtures tend to be somewhat more flexible and are capable of generating wider varieties of shapes for the probability distributions than generalized distributions. 
Melick and Thomas [1997] use mixtures of three lognormal distributions. They apply their method to American options on crude oil futures, and they use appropriate bounds on the American option prices, which account for the possibility of early exercise. Ritchey [1990] gives examples of option prices where the risk-neutral distribution of the log-returns is a mixture of normal distributions.

\section{Non-parametric methods}

Non-parametric methods try to achieve greater flexibility in fitting the risk-neutral distribution to option prices, too. However, rather than requiring a parametric form of the distribution, they allow more general functions. Again, we divide the methods into three groups. First, kernel methods are conceptually related to regressions in that they try to fit a function to observed data. The main difference is that kernel regression does not specify the parametric form of the function. Second, maximum entropy methods find a non-parametric probability distribution, which is as close as possible in terms of information content to a prior distribution while satisfying certain constraints such as pricing observed options correctly. Third, curve fitting methods are a loosely associated group of methods which try to fit the implied volatilities or the risk-neutral probability as best as possible with some flexible function. A commonly used measure of fit is the sum of squared distances between observed option prices and option prices suggested by the curve fitting method.

Kernel methods are based on the concept that each data point (say the implied volatility at a certain strike price) should be viewed as the center of a region where the true function could be lying. The further away a point is from the observed data point, the less likely it is that the true function goes through that distant point. A kernel $(\mathrm{k}(\mathrm{x}))$, which is often assumed to be the normal 
distribution $\left(n(x)=\frac{1}{\sqrt{2 \pi}} e^{-.5 x^{2}}\right)$, measures the corresponding drop in likelihood when we move away from the data point. Thus, if we observe implied volatilities across strike prices $\sigma_{i}\left(K_{i}\right)$ then the kernel regression in one dimension is:

$$
\sigma(K)=\frac{\sum_{i=1}^{n} k\left(\frac{K-K_{i}}{h}\right) \sigma_{i}}{\sum_{i=1}^{n} k\left(\frac{K-K_{i}}{h}\right)}
$$

where $\mathrm{h}$ is the bandwidth, which governs the smoothness of the kernel regression. Kernel regressions tend to be very data intensive, which limits their use. Also, they tend to fill in missing data in a non-intuitive way. Thus, in a downward sloping implied volatility smile where a range of strike prices has no observations, we would find question-mark shaped segments filling those gaps, rather than smooth interpolations across the gaps.

Ait-Sahalia and Lo [1998a] use kernel estimators across the five dimensions of stock price, strike price, time-to-expiration, interest rate, and dividend yield. They also use a reduced set of three dimensions, which are forward price, strike price, and time-to-expiration. Pritsker [1997] employs their methodology in order to investigate the risk-neutral distribution of interest rates. However, he warns that the presence of persistence in interest rates violates the assumption of independently and identically distributed observations and thus the asymptotic results of AitSahalia and Lo [1998a] do not need to hold. Indeed, Pritsker [1997] finds severe finite sample biases. In a further study, Rookley [1997] suggests a bivariate kernel estimator across time-toexpiration and moneyness. In addition, he proposes to model the stochastic process of implied intraday volatilities. 
Maximum Entropy methods effectively try to maximize the amount of missing information given the constraints, that is, they try to be the least prejudiced with respect to unknown or missing information. In order to implement these ideas - and somewhat similar to a Bayesian framework - a prior distribution $\left(\mathrm{Q}_{\mathrm{i}}\right)$ is chosen and the posterior risk-neutral distribution $\left(\mathrm{P}_{\mathrm{i}}\right)$ is found by maximizing the cross-entropy:

$$
-\sum_{i} P_{i} \ln \left(\frac{P_{i}}{Q_{i}}\right)
$$

subject to constraints such as positivity of the probabilities, summing of the probabilities to one, and correct pricing of options and the underlying. If the prior distribution happens to be the uniform distribution, then the cross-entropy reduces to the simple entropy $-\sum_{i} P_{i} \ln P_{i}$.

Buchen and Kelly [1996] use the uniform and the lognormal distribution as prior distributions and show some simulation results. Stutzer [1996] derives the risk-neutral distribution where he uses the historical distribution of the asset price as a prior. He only constrains the risk-neutral distribution to price the underlying asset correctly. Then, he prices the options and finds evidence of a volatility skew. However, the skew depends rather delicately on the length of the historical sample used to derive the historical distribution.

Curve fitting methods are a broad class of methods where either the function of implied volatilities across strike prices or the risk-neutral distribution itself is approximated by some general function. The functions involved tend to be flexible and smooth such as the class of polynomials in the strike price. For added flexibility, such polynomial segments can be pieced together in a smooth fashion into splines. This is achieved by connecting the segments at socalled knots by matching the levels and some derivatives of the segments at the knots. The main advantage of splines is that the knots serve to localize the fit of the polynomials and thereby avoid 
oscillating and extreme values of the polynomials in regions with little data. Finally, smoothness can be made an explicit objective in non-parametric curve fitting methods by finding a function through the data which fits the data in a least squares sense and also minimizes the integral of squared second derivatives, which accounts for the cumulative curvature of the function. We will now investigate the methods fitting the smile first and then the methods fitting the risk-neutral distribution in the next paragraph.

Shimko [1993] introduced the first method of curve fitting to the smile when he fitted a quadratic polynomial. He then translates the implied volatilities into option prices and can derive the risk-neutral distribution from the second derivatives of the (future) option prices with respect to strike prices according to Breeden and Litzenberger [1978]. He finally grafts lognormal tails onto the risk-neutral distribution. Malz [1997] proposes a variation of this method where he fits a quadratic polynomial to the implied volatilities across call option deltas instead of strike prices. The deltas are the derivatives, according to the Black-Scholes formula, of the option prices with respect to the stock price. The benefit is that he can avoid grafting tails onto the distribution. Shimko's [1993] approach is extended in Brown and Toft [1999] to seventh order splines. Campa, Chang, and Reider [1998] use cubic splines to fit the volatility smile. Aparicio and Hodges [1998] use cubic B-splines that belong to a particular family of polynomials used for the segments. Rosenberg and Engle [1997] use a polynomial fitted to the log of the smile, which then automatically prevents negative implied volatilities. Rosenberg [1996] extends this method to the bivariate case. Jackwerth [1999] maximizes the smoothness of the smile and can then control the tradeoff between option price fit and smoothness explicitly. Also, the calculations in this group do not require iterations and can be computed in one pass and closed form. However, they do not guarantee that the resulting probabilities will always be positive, a condition which has to be checked separately. 
The second group of curve fitting methods tries to approximate the risk-neutral distribution directly. Rubinstein [1994] minimizes the distance of discretized probabilities to a lognormal prior distribution subject to correctly pricing the observed options and the underlying. Jackwerth and Rubinstein [1996] shows that differences in the way to measure this distance, for example by computing squared or absolute deviations or cross-entropy, does not affect the resulting risk-neutral distribution by much as long as we observe more than a few option prices. Jackwerth and Rubinstein [1996] also introduce a new method, which does not need a prior distribution. They maximize the smoothness of the risk-neutral distribution subject to correctly pricing the options. Mayhew [1995] uses the same idea of maximizing the smoothness of the distribution and approximates the density with cubic splines. Hartvig, Jensen, and Pedersen [1999] suggest a related method where they build up the logarithm of the risk-neutral distribution from piece-wise linear segments. In a Bayesian framework they then use an exponential prior distribution and find the risk-neutral distribution according to the observed options prices.

Although there are numerous methods for recovering the risk-neutral distributions, the results tend to be rather similar unless we are faced with only very few option prices. The reason is that if we observe a set of only 10 to 15 options then the collective set of no-arbitrage bounds is so tight that the price of an additional option, which has not been priced yet, is often determined to within the bid/ask spread. This holds to a lesser extent in the tails of the distribution but is a rather accurate assessment of the situation for near-the-money options. Jackwerth and Rubinstein [1996] make this point, and as a result, one can use just about any reasonable method and the resulting risk-neutral distributions will be rather similar. Campa, Chang, and Reider [1998] corroborate this finding when they use three alternative methods, cubic splines, Rubinstein's [1994] minimal distance method, and mixtures of lognormal distributions, to fit the volatility smile of options on exchange rates. Again with similar results, Coutant, Jondeau, and Rockinger 
[1998] use three alternative methods, a mixture of lognormal distributions, Hermite polynomial expansion, and maximum entropy, to fit options on bond futures. As a practical guideline, approximating the smile tends to be easier than directly approximating the probability distribution: in the Black-Scholes reference case, the smile is just a flat line as opposed to the lognormal distribution, which is highly non-linear. This advantage carries over to the actual, skewed volatility smiles, too.

\section{Applications}

One straightforward application of the risk-neutral density is to price any payoff with the same time-to-expiration. Thus, if we have a set of liquid options from which to derive the riskneutral distribution, we can then use it to price illiquid options. These options might have exotic payoff but they must be European options since the risk-neutral distributions cannot handle early exercise without further assumptions, which we will investigate in section II below.

A number of papers have investigated the shape of the risk-neutral probability distribution around announcements of economic news. Campa and Chang [1996 and 1998] and Campa, Chang, and Refalo [1999] use cross-rate foreign exchange options from the exchange rate mechanism (ERM) and Brazilian real/US dollar, respectively, in order to assess how credible the commitment to exchange rate target zones is. They assess the minimal and maximal risk-neutral probability associated with the exchange rate leaving the target band. The papers show that the option markets often raised their probability assessment prior to exchange rate crisis and realignments. Also concerning the ERM, Mizrach [1996] finds evidence in the option prices that the market already incorporated the potential withdrawal of the pound from the ERM ahead of the actual announcement. He fits each day a mixture of three lognormal distributions to the option 
prices. His finding is that the option markets seem to increase their risk-neutral probability assessment of a devaluation already a few days prior to the actual devaluation. McCauley and Melick [1996] and Malz [1997] investigate general market sentiments in foreign exchange markets by quite literally interpreting graphs of the change in the shape of the risk-neutral distribution for different times. Bahra [1997] argues similarly when investigating the change in shape of the risk-neutral distribution around announcements of an inflation report and of the German money supply (M3). He then goes on to provide a general discussion of interpreting graphs of risk-neutral probability distributions in assessing monetary conditions and credibility, identifying market anomalies, and investigating the timing and effectiveness of monetary operations. Finally, Brenner, Eom, and Landskroner [1996] imply the foreign exchange rate from option prices but they do not use the whole risk-neutral distribution.

Söderlind and Svensson [1996] fit mixtures of lognormal distributions to options on bonds in order to recover risk-neutral distributions of interest rates and provide graphs of the distributions on two dates. Coutant, Jondeau, and Rockinger [1998] investigate the daily implied interest rate distribution and focus on the time around the French snap elections. Jondeau and Rockinger [1998b] analyze the same elections using the options on the franc/deutschemark exchange rate. Both papers use a number of different methods, among them mixtures of lognormals and Hermite polynomial expansions, which all yield similar results. They find that the elections were already anticipated in the market before the actual announcement since the volatility of the risk-neutral distributions increased. Melick and Thomas [1997] use the crude oil futures option market in order to assess the impact of the Gulf War on the risk-neutral distributions. They fit a mixture of three lognormal distributions to the daily option prices and plot the implied risk-neutral probabilities of large price moves relative to the current future price. Using the same method, Leahy and Thomas [1996] investigate the impact of the Quebec 
referendum on the Canadian foreign exchange market. As a general observation, there is a danger in reading too much information into the graphs of risk-neutral distributions. After all, they are not graphs of actual distributions but mental constructs, which are used for pricing purposes. Also, none of the empirical papers investigating the change in shape of the risk-neutral distribution provides a formal argument when the shapes should be considered different. So far, they tend to appeal to some intuitive notion along the lines of "tails are looking fatter after the event" or "a certain moment increased over time". Such judgements do not account for estimation error due to observing only noisy option prices. In particular, none of the papers provides for a statistical test of the significance nor does any of the papers control for exogenous factors, which could have caused the change in shape. For example, increased volatility could have been driven by a market-wide rise in volatility rather than by the particular economic announcement.

A rather different line of research has been looking at the relationship between probabilities and utility functions in a representative agent setting. There, marginal utility (U') is closely related to the ratio of risk-neutral to subjective probabilities (Q) where one uses the historical distribution as a proxy for the subjective probabilities:

$$
U^{\prime}=\frac{\lambda P}{r^{T} Q}
$$

where $\lambda$ is the shadow price of the budget constraint.

Rosenberg and Engle [1997] and Aï-Sahalia and Lo [1998b] derive such marginal utility functions. Jackwerth [1999] goes on to recover implied risk aversion functions:

$$
R A=-\frac{U^{\prime \prime}}{U^{\prime}}=\frac{Q^{\prime}}{Q}-\frac{P^{\prime}}{P}
$$

The risk aversion functions turn out to be well-behaved pre-crash and seem to imply mispricing in the option market post-crash. Stutzer [1996] uses maximum entropy arguments to find the risk- 
neutral distribution, which is most compatible with the historical distribution subject to having the mean equal to the risk-free rate. As a general observation we find that out of the three entities risk-neutral distribution, subjective distribution, and utility function, we can derive one as long as we know the other two. Moreover, all involved quantities are difficult to estimate. Risk-neutral distributions are rather well understood, and subjective distributions can be derived from historical distributions with some assumptions on the updating of beliefs by investors. However, utility functions are least understood and notoriously hard to estimate.

\section{Implied Binomial Trees}

Once we derive the risk-neutral distribution of the terminal asset price, it is tempting to ask how the asset price can reach that terminal distribution. In other words, we try to model a stochastic process for the asset price that results in the same terminal distribution, which is implied in the option prices. Unfortunately, there is no such unique stochastic process. Moreover, even if we knew the risk-neutral distribution for every point in time between today and the longest dated time-to-expiration, there would still not be a unique stochastic process. The reason is that the stock price could evolve, for example, either according to a diffusion process, a jump process, or to any number of alternative processes, which can involve jumps or additional stochastic factors such as stochastic interest rates or stochastic volatility.

However, if we are willing to limit ourselves to the class of generalized one-dimensional diffusion processes and if we are willing to rely solely on the observed option prices in the market, then implied binomial trees are a potential solution. We can view implied binomial trees as discretizations of generalized one-dimensional diffusions where the generalized volatility parameter is allowed to be a function of time and the asset price. This extends the standard 
diffusion of the Black-Scholes formula where the volatility parameter is constant across time and asset price. The risk-neutral drift in either the standard or the generalized diffusion processes is fully determined by the risk-free rate. Discretizing the volatility surface as a binomial tree is then one convenient choice but not the only one.

\section{One-Factor Implied Trees}

In order to introduce implied binomial trees, we start out with a simple two step example within a standard Cox, Ross, and Rubinstein [1979] binomial tree. This binomial tree is the discretization of the continuous-time Black-Scholes model. We assume that the volatility is 0.2 , the current stock price $\left(\mathrm{s}_{\mathrm{i}}\right)$ is 1 , and the interest return (r) is 1.1. Also, we assume that there are no dividends being paid and that each time step spans one year.

\section{EXHIBIT 1, about here}

\section{EXHIBIT 2, about here}

Let us now complicate our simple world by introducing a volatility smile. In particular, for every $10 \%$ moneyness subtracted (added) from the at-the-money option, volatility increases (decreases) by a factor of 1.1. Thus, a call option with strike price 1.1 has an implied volatility of $0.2 / 1.1=0.1818$ and, with two years until expiration, a price of 0.1497. Then, Rubinstein [1994] suggests building an implied binomial tree backward from the terminal distribution to the starting date. We take the terminal stock prices from the standard binomial tree. The implied risk-neutral probabilities at the terminal nodes of the implied binomial tree have to price the bond, the stock, and the option, respectively: 


\begin{tabular}{|c|c|c|c|c|c|c|}
\hline 0.8264 & $=(1$ & $\cdot \mathrm{p}_{1}$ & +1 & $\cdot \mathrm{p}_{2}$ & +1 & $\left.\cdot \mathrm{p}_{3}\right) / 1.1^{2}$ \\
\hline 1 & $=(0.6703$ & $\cdot \mathrm{p}_{1}$ & +1 & $\cdot \mathrm{p}_{2}$ & +1.4918 & $\left.\cdot \mathrm{p}_{3}\right) / 1.1^{2}$ \\
\hline 0.1497 & $=(0$ & $\cdot \mathrm{p}_{1}$ & +0 & $\cdot \mathrm{p}_{2}$ & +0.3918 & $\left.\mathrm{p}_{3}\right) / 1.1^{2}$ \\
\hline
\end{tabular}

Upon solving the system of equations, we find that the resulting probabilities are $\mathrm{p}_{1}=$ $0.0527, \mathrm{p}_{2}=0.485$, and $\mathrm{p}_{3}=0.4623$. A key assumption is that the path probabilities of reaching the same terminal asset price are equal. Then, a unique implied binomial tree can be derived backward in time which is guaranteed to be arbitrage-free. The nodal probability at the terminal center node of 0.4850 is being evenly split up and ends up at the two nodes of the intermediate step. Thus the upper intermediate node receives a total probability of 0.7048 which derives from a probability of 0.4623 of reaching the next higher node and of $0.2425(=0.4850 / 2)$ of reaching the next lower node. The probability at the lower intermediate node is calculated similarly. Finally, we can solve for the upper intermediate stock price. First we need the transition probability of moving up which is $0.4623 / 0.7048=0.6559$ and of moving down which is 0.2425 $/ 0.7048=0.3441$. The stock price is then $(0.6559 \cdot 1.4918+0.3441 \cdot 1) / 1.1=1.2023$. The stock price at the lower intermediate node is calculated similarly.

\section{EXHIBIT 3, about here}

\section{EXHIBIT 4, about here}

Rubinstein's [1994] approach has two drawbacks. First, prices of options expiring earlier than the terminal date cannot be used in constructing the tree. Second, the assumption of equal path probabilities is rather arbitrary and restrictive. Jackwerth [1997] addresses these concerns by generalizing the implied binomial tree through the introduction of a simple weight function. This weight function governs the backward construction of the implied binomial tree and Rubinstein's [1994] tree corresponds to a special, linear weight function. With these generalizations we are 
able to incorporate information from times other than the end of the tree and also from American and exotic options.

Going back to our example, a call option with strike price 1.1 and time-to-expiration of one year is valued at 0.0724 . However, the option is not correctly priced on the implied binomial tree where it is valued at $(0.7048 \cdot 0.1023+0.2952 \cdot 0) / 1.1=0.0656$. We achieve the appropriate pricing by changing the split according to which the probability at the terminal center node is being distributed backwards. The implied binomial tree splits the probability evenly whereas the - properly fitted - generalized binomial tree sends $0.4190 \cdot 0.4850=0.2032$ to the intermediate upper node and $0.5810 \cdot 0.4850=0.2818$ to the intermediate lower node. Thus the upper intermediate node receives a total probability of $0.6655=0.4623+0.2023$. The probability at the lower intermediate node is calculated similarly. Finally, we can solve for the intermediate stock prices as we did above. The resulting generalized binomial accurately prices the call option at 0.0724 .

\section{EXHIBIT 5, about here}

\section{EXHIBIT 6, about here}

Derman and Kani [1994] introduce an alternative implied tree. It is constructed forward by adding the nodes for a new time-step based on the information contained in a particular set of option prices. These options have strike prices equal to the asset prices of the previous step and they expire at the next time-step. Thus, options with different maturities can be incorporated; but in order to obtain the required set of option prices, extensive inter- and extrapolation of the observed option prices is needed. Also, the tree is not necessarily arbitrage-free since negative probabilities can occur. These negative probabilities have to be reset to values between zero and one in an ad hoc fashion. As a result, Derman and Kani [1994] trees become numerically unstable, especially when the number of steps is large. For an improvement, Derman, Kani, and 
Chriss [1996] suggest trinomial trees where the additional degrees of freedom are used in order to ameliorate the numerical problems. Chriss [1996] shows how to incorporate American options but he needs a costly optimization step at each node of the implied tree. Barle and Cakici [1998] add some other improvements to increase the stability of the original Derman and Kani [1994] trees. For one, they suggest to let the center nodes of the tree be aligned with the forward price rather than with the current stock price. Also, whenever a new option is needed to provide information about the next node of the tree, they advocate using the option with strike price equal to the forward price of the previous node's stock price. This differs from using the previous node's stock price itself as Derman and Kani [1994] originally suggested. Finally, Barle and Cakici [1998] recommend using the Black-Scholes formula in order to price the needed options as opposed to pricing them on a binomial tree.

\section{EXHIBIT 7, about here}

\section{EXHIBIT 8, about here}

The implied binomial tree by Derman and Kani [1994], with the corrections suggested in Barle and Cakici [1998], requires the following calculations. We follow closely the notation of Barle and Cakici [1998]. The lower intermediate stock price follows from ( $\mathrm{i}=1)$ :

$$
S_{i}=F_{i} \frac{\lambda_{i} F_{i}-\Delta_{i}^{C}}{\lambda_{i} F_{i}+\Delta_{i}^{C}}=1.1 \frac{1 \cdot 1.1-0.0797}{1 \cdot 1.1+0.0797}=0.9514
$$

where $F_{i}=s_{i}\left(\frac{r}{d}\right)^{\Delta t}=1.1, \mathrm{~s}_{\mathrm{i}}$ is today's stock price, $\Delta \mathrm{t}$ is one time-step of one year, $\lambda_{\mathrm{i}}$ is the statecontingent price today $(=1), \Delta_{i}^{C}=r^{\Delta t} C\left(F_{i}, t_{n+1}\right)-\sum_{j=i+1}^{n} \lambda_{j}\left(F_{j}-F_{i}\right)$, and $\mathrm{C}\left(\mathrm{F}_{\mathrm{i}}, \mathrm{t}_{\mathrm{n}+1}\right)=0.0724$ is the call expiring next period with strike price $F_{i}$. The upper intermediate stock price follows from $S_{i+1}$ $=\mathrm{F}_{\mathrm{i}}^{2} / \mathrm{S}_{\mathrm{i}}=1.21 / 0.9514=1.2718$. The upper intermediate probability can then be derived from: 


$$
p_{i}=\frac{F_{i}-S_{i}}{S_{i+1}-S_{i}}=\frac{1.1-0.9514}{1.2718-0.9514}=0.4638
$$

and the lower intermediate probability is $1-0.4638=0.5362$.

In order to construct the terminal step, we start with the center node $S_{(n / 2)+1}=s_{1}\left(\frac{r}{d}\right)^{t_{n+1}}=1 \cdot 1^{2}=1.21$, where $\mathrm{n}=2$. Next we find the upper terminal node (i=2):

$$
S_{i+1}=\frac{\Delta_{i}^{C} S_{i}-\lambda_{i} F_{i}\left(F_{i}-S_{i}\right)}{\Delta_{i}^{C}-\lambda_{i}\left(F_{i}-S_{i}\right)}=\frac{0.03 \cdot 1.21-0.4216 \cdot 1.399(1.399-1.21)}{0.03-0.4216(1.399-1.21)}=1.5131
$$

where $F_{i}=s_{i}\left(\frac{r}{d}\right)^{\Delta t}=1.2718 \cdot 1.1=1.399, \mathrm{~s}_{\mathrm{i}}$ is the stock price at the upper intermediate node, $\lambda_{\mathrm{i}}=$ $\mathrm{p}_{\mathrm{i}} / \mathrm{r}^{\Delta \mathrm{t}}=0.4638 / 1.1=0.4216$ is the state-contingent price at the upper intermediate node, and $\mathrm{C}\left(\mathrm{F}_{\mathrm{i}}, \mathrm{t}_{\mathrm{n}+1}\right)=0.03$ is the call expiring in the last period with strike price $\mathrm{F}_{\mathrm{i}}$. Finally, we find the lower terminal node $(\mathrm{i}=1)$ :

$$
S_{i}=\frac{\lambda_{i} F_{i}\left(S_{i+1}-F_{i}\right)-\Delta_{i}^{P} S_{i+1}}{\lambda_{i}\left(S_{i+1}-F_{i}\right)-\Delta_{i}^{P}}=\frac{0.4875 \cdot 1.0465(1.21-1.0465)-0.0467 \cdot 1.21}{0.4875(1.21-1.0465)-0.0467}=0.8152
$$

where $F_{i}=s_{i}\left(\frac{r}{d}\right)^{\Delta t}=0.9514 \cdot 1.1=1.0465, \mathrm{~s}_{\mathrm{i}}$ is the stock price at the lower intermediate node, $\lambda_{\mathrm{i}}=$ $\mathrm{p}_{\mathrm{i}} / \mathrm{r}^{\Delta \mathrm{t}}=0.5362 / 1.1=0.4875$ is the state-contingent price at the lower intermediate node, $\Delta_{i}^{P}=r^{\Delta t} P\left(F_{i}, t_{n+1}\right)-\sum_{j=1}^{i-1} \lambda_{j}\left(F_{j}-F_{i}\right)$, and $\mathrm{P}\left(\mathrm{F}_{\mathrm{i}}, \mathrm{t}_{\mathrm{n}+1}\right)=0.0467$ is the put expiring in the last period with strike price $F_{i}$. As a last step, we calculate the transition probability between the upper intermediate node and the upper terminal node:

$$
p_{i}=\frac{F_{i}-S_{i}}{S_{i+1}-S_{i}}=\frac{1.399-1.21}{1.5131-1.21}=0.6236
$$

and similarly the transition probability between the lower intermediate node and the center terminal node: 


$$
p_{i}=\frac{F_{i}-S_{i}}{S_{i+1}-S_{i}}=\frac{1.0465-0.8152}{1.21-0.8152}=0.5859
$$

We can then calculate the probabilities of reaching the terminal nodes. The lower node receives $0.5362 \cdot(1-0.5859)=0.222$, the center node receives $0.4638 \cdot(1-0.6236)+0.5362$. $0.5859=0.4887$, and the upper node receives $0.4638 \cdot 0.6236=0.2892$.

Dupire [1994] suggests a trinomial tree similar to Derman and Kani [1994], which is also forward constructed, and the nodes within each additional step are determined by the prices of options expiring on that time step. Computationally, the generalized binomial tree by Jackwerth [1997] is a good choice among the backward constructed trees. It offers the flexibility of incorporating information on exotic and American options and it is guaranteed to be arbitrage free. The computations are simple but the calibration can involve a non-linear optimization in order to fit the tree to non-European options. Alternatively, the tree by Barle and Cakici [1998] is a good choice among the forward constructed trees. It can handle only European options and can still exhibit arbitrage violations, albeit much less frequently than the Derman and Kani [1994] trees. The calculations are slightly more convoluted and the implied volatilities of observed options have to be interpolated and extrapolated in order to price the option required to construct the next node of the tree.

\section{Two-Factor Implied Trees}

Paralleling the development of parametric option pricing models, implied binomial tree models have been extended to multiple factors. So far in the literature, there are two implied tree models, which can incorporate stochastic volatility as well as the usual process of the asset price. 
Derman and Kani [1998] start out by fitting a trinomial implied tree to the observed option prices. The transition probabilities from node to node are fixed at this stage. In order to incorporate stochastic volatility, they allow those transition probabilities to change according to a separate stochastic process, which has to be specified exogenously. Conceptually, their new tree is related to the interest rate model of Heath, Jarrow, and Morton [1992] and suffers from similar drawbacks: the resulting process is generally non-Markovian since the evolution of the volatility surface is path-dependent. Thus, option prices have to be computed through an expensive MonteCarlo simulation. Similar in spirit but computationally simpler is the approach of Ledoit and Santa-Clara [1998] who model stochastic implied volatilities as opposed to the stochastic local volatilities in Derman and Kani [1998]. They can then derive the conditions under which the joint process of stock price and volatility surface is arbitrage free. This joint process can be calibrated to observed option prices. Illiquid or exotic options can then be priced via Monte-Carlo simulation.

In a related paper, Britten-Jones and Neuberger [1999] are able to describe the set of continuous stochastic processes, which are compatible with the observed option prices. In particular, these models share the same volatility forecasts. Similar to Derman and Kani [1998] they also use implied trinomial trees. However, Britten-Jones and Neuberger [1999] restrict the stochastic volatility component to be a Markov chain by discretizing volatility into a set of volatility states. Transition probabilities are assigned to move from one volatility state into the next. Finally, they adjust the transition probabilities so that the observed option prices are matched. While losing some of the generality of Derman and Kani [1998], their tree is faster to compute and no simulations are needed in order to price options. However, neither of these stochastic volatility implied trees has yet been empirically tested. 


\section{Empirical Tests}

Dumas, Fleming, and Whaley [1998] develop deterministic volatility functions, which are polynomials in time and asset price, and use these functions as volatility surfaces of generalized diffusions. They alternatively interpret these functions as implied volatility surfaces of the options. The latter "ad-hoc" model performs slightly better and we will describe its estimation in more detail. The authors collect option prices on the S\&P500 index with time-to-expiration from 6 to 100 days. On every Wednesday from June 1998 to December 1993, they fit the volatility surface to the observed options on that day. They then wait for a week and use the calibrated surface to forecast the option prices on that following Wednesday where they condition on the passage of one weeks time and the movement in the asset price. The average root-mean-squared prediction error is $47-59$ cents for the options with time-to-expiration of more than 70 days. The authors compare this prediction error to an average bid/ask spread of 47 cents. However, at this point one should not throw the baby out with the bath-water and dismiss implied binomial trees altogether: competing fully parametric models do not necessarily perform much better. Bakshi, Cao, and Chen [1997] fit parametric stochastic jump, stochastic volatility models to S\&P500 index options during June 1988 to May 1991. They predict one-day ahead option prices and report average errors for options with time-to-expiration from 60 to 180 days. These errors are about 40 cents even for their best performing models. While this paper does not intend to cover the literature on fitting generalized stochastic processes to option prices, we want to just mention some few articles. Malz [1996] uses option prices to estimate a jump-diffusion and finds that the option implied realignment probabilities within the European monetary system increased ahead of

the actual realignment. A wealth of information on fitting stochastic jump and stochastic 
volatility processes to option prices is contained in the papers by Bates [1991, 1996a and b, $1998]$.

Also, Jackwerth and Rubinstein [1998] compare implied binomial trees, parametric models (among them a stochastic volatilty model), and naïve trader rules of thumb. These naïve rules assume that implied volatility is a function of strike price (absolute smile rule) or moneyness (relative smile rule) and does not change as time passes. The authors fit all their models to daily observations of options on the S\&P500 index from April 1986 to December 1995. They then calculate the average prediction errors for 10-day (= two week) forecasts of options with time-to-expiration from 135 to 215 days. Those errors range from 75 cents for the implied binomial tree to 57 cents for the naïve trader rules with the parametric models at about 78 cents. Given that the empirical standard deviation of these errors is 80 to 130 cents, we come to the conclusion that none of the models performs extraordinarily well and that implied binomial trees perform about as well as the parametric models and the naïve trader rules.

\section{Other Non-Parametric Models}

Implied binomial trees discretize the volatility surface of a generalized one-dimensional diffusion in a particularly convenient way but there are other choices. An alternative was developed in Dumas, Fleming, and Whaley [1998] under the name of deterministic volatility models. Here, the volatility surface is discretizes onto a pre-specified (rectangular) grid in time and asset prices. Finite difference methods are then used to price the options based on the volatility surface. Andersen [1995] uses the same methodoly and highlights different choices for the finite difference method, such as implicit vs semi-implicit. He also points out the computational advantage of deterministic volatility models over implied binomial trees when 
pricing exotic options with discontinuous payoffs, such as barrier options. Again using a deterministic volatility model and finite difference pricing of the options, Bodurtha and Jermakyan [1996a and b] and Lagnado and Osher [1997] require in addition that the volatility surface has to be smooth. However, both sets of authors acknowledge that their respective methods are rather expensive computationally. Coleman, Li, and Verma [1998] also try to impose some smoothness requirement on the volatility surface. They employ bicubic splines for spanning the volatility surface, which reduces the computational requirements. For pricing purposes they use a finite difference approach. Similar in spirit is Avellaneda et al. [1996] who use a crossentropy maximization to fit the volatility surface to be close to some prior surface and to fit the observed option prices. However, their approach suffers from numerical difficulties as their volatility surface is riddled with spikes at the data points. Bouchouev and Isakov [1997] build up the volatility surface from rather complex functions, which involve integral evaluations. They assume that volatility is independent of time and can then find formulas for the volatilty surface. However, the independence assumption somewhat defeats the purpose of having a deterministic volatility model to begin with. Their approach then effectively collapses to a very involved method of finding the risk-neutral distribution, as we described in section I. Carr and Madan [1998] work within the framework of a generalized one-dimensional diffusion process. They add structure to the volatility surface by assuming that the asset prices itself is path-independent, that is it only depends on time and the level of the driving Brownian motion. They can then determine the whole volatility surface by fitting it to one set of observed option prices with common timeto-expiration.

In the case of implied binomial trees, the model is fitted to the observed option prices but there is still some structure in the model. For example, the asset price can only move up or down over the next instant of time. Laurent and Leisen [1998] leave this framework by still using a pre- 
specified grid of times and asset prices but they model the transition probabilities as a Markov chain. Since the asset price can now move to more nodes than just the next higher and lower one, the market is no longer complete. Then, the risk-neutral distribution is not uniquely identified and there are two choices. One has to either pick one of the distributions or one can only establish bounds around the observed option prices. The authors suggest either picking the distribution, which yields the highest prices for all non-traded assets, or using cross-entropy maximization to find a distribution, which is close to a prior distribution and also fits observed option prices. In related work, Samperi [1996] investigates incomplete markets and gives expressions for the bounds on option prices if the volatility surface is bounded by a highest and lowest value. He then assumes that investors follow risk-minimizing trading strategies and is able to derive a unique implied tree as a solution.

Beyond these model lie the fully non-parametric models such kernel methods, which discard even the little remaining structure of generalized diffusion processes and view the option pricing model as a non-linear surface of option prices or implied volatilities which is fitted to the observed prices. For example, Ait-Sahalia and Lo [1998a] fit a five-dimensional surface of option implied volatilities across stock price, strike price, time-to-expiration, interest rate, and dividend yield. Similarly, Hutchinson, Lo, and Poggio [1994] use neural networks to recover an approximation of the Black-Scholes formula from simulated option prices and to fit observed prices of options on S\&P500 futures. Neural networks are nonlinear regression methods where the functional form of the regression is very flexible due to the multi-layered use of simple functions such as $f(x)=\frac{1}{1+e^{-x}}$. These functions are applied to the data, the results are then weighed by the regression coefficients and added together, and finally the functions are again 
applied to the sums. More recently, Herrmann and Narr [1997] use the same methodology on German index option prices, which exhibit a volatility smile.

\section{Conclusion}

Ever since the crash of 1987, researchers have realized that the Black-Scholes model could no longer explain the observed volatility smile in the index options markets. Also, options on individual stocks and exchange rates exhibit volatility smiles. One way of dealing with the situation led to a renewed interest in parametric extensions of the Black-Scholes model, which incorporate stochastic volatility and stochastic jumps. However, an alternative approach is to use the observed option prices in order to learn more about the stochastic process of the asset price. Given a set of option prices with a specific time-to-expiration, we can find risk-neutral probability distributions, which support these prices. A number of studies assess the change in these probability distributions due to news events. Furthermore, we can also learn from observed option prices about the stochastic process of the asset price, leading up to the terminal probability distribution. Implied binomial trees allow us to recover such stochastic processes, and extensions are available, which can incorporate stochastic volatility processes as well. In empirical tests, implied binomial trees perform as well (or as poorly) as both parametric models and naïve trader rules (such as the absolute and relative smile rules). 


\section{References}

Abadir, K., and M. Rockinger. "Density-Embedding Functions." Working Paper, HEC, 1997.

Abken, P., D. Madan, and S. Ramamurtie. "Estimation of Risk-Neutral and Statistical Densities by Hermite Polynomial Approximation: With an Application to Eurodollar Futures Options." Working Paper, Federal Reserve Bank of Atlanta, 1996a.

Abken, P., D. Madan, and S. Ramamurtie. "Pricing S\&P500 Index Options Using a Hilbert Space Basis.” Working Paper, Federal Reserve Bank of Atlanta, $1996 \mathrm{~b}$.

Ait-Sahalia, Y. and A. Lo. "Nonparametric Estimation of State-Price Densities Implicit in Financial Asset Prices.” Journal of Finance, 53, No. 2, (1998a), pp. 499-547.

Ait-Sahalia, Y. and A. Lo. "Nonparametric Risk Management and Implied Risk Aversion." Working Paper, University of Chicago, 1998b. Journal of Econometrics, forthcoming.

Andersen, L. "The Equity Option Volatility Smile: An Implicit Finite Difference Approach." Working Paper, General Re Financial Products Corp., New York, 1995.

Aparicio, S., and S. Hodges. "Implied Risk-Neutral Distribution: A Comparison of Estimation Methods.” Working Paper, Warwick University, 1998.

Avellaneda, M., C. Friedman, R. Holmes, and D. Samperi. "Calibrating Volatility Surfaces Via Relative-Entropy Minimization.” Working Paper, Courant Institute, New York University, 1996.

Bahra, B. "Implied Risk-Neutral Probability Density Functions from Option Prices: Theory and Application.” Working Paper, Bank of England, London, 1997.

Bakshi, G., C. Cao, and Z. Chen. "Empirical Performance of Alternative Option Pricing Models." Journal of Finance, 52, No. 5 (1997), pp. 2003-2049.

Banz, R. and M. Miller. "Prices for State-Contingent Claims: Some Estimates and Applications." Journal of Business, 51 (1978), pp. 653-672. 
Barle, S., and N. Cakici. "How to Grow a Smiling Tree." Journal of Financial Engineering, 7 , No. 2 (1998), pp. 127-146.

Bates, D. "The Crash of '87: Was It Expected? The Evidence from Options Markets." Journal of Finance, 46, No. 3 (1991), pp. 1009-1044.

Bates, D. "Jumps and Stochastic Volatility: Exchange Rate Processes Implicit in Deutsche Mark Options." Review of Financial Studies, 9, No. 1 (1996a), pp. 69-107.

Bates, D. "Testing Option Pricing Models." In Maddala, G., and C. Rao, ed, Handbook of Statistics, v. 14: Statistical Methods in Finance. Amsterdam: Elsevier, 1996b, pp. 567-611.

Bates, D. "Post-'87 Crash Fears in S\&P 500 Futures Options," Journal of Econometrics, 1998, forthcoming.

Bernardo, A., and O. Ledoit. "Gain, Loss and Asset Pricing." Journal of Political Economy, 1999, forthcoming.

Black, Fischer, and Myron Scholes. "Pricing of Options and Corporate Liabilities." Journal of Political Economy, 81 (1973), pp. 637-659.

Bodurtha, J., and M. Jermakyan. "Non-Parametric Estimation of an Implied Volatility Surface." Working Paper, Georgetown University, 1996a.

Bodurtha, J., and M. Jermakyan. "Regular Smiles." Working Paper, Georgetown University, 1996b.

Bookstaber, R., and J. McDonald. "A General Distribuion for Describing Security Price Returns.” Journal of Business, 60, No. 3 (1987), pp. 401-424.

Bouchouev, I., and V. Isakov. "The Inverse Problem of Option Pricing." Inverse Problems, 13 (1997), pp. L11-L13.

Breeden, D. and R. Litzenberger. "Prices of State-Contingent Claims Implicit in Options Prices." Journal of Business, 51 (1978), pp. 621-651. 
Brenner, M., and Y. Eom. "No-Arbitrage Option Pricing: New Evidence on the Validity of the Martingale Property.” Working Paper, New York University, 1997.

Brenner, M., Y. Eom, and Y. Landskroner. "Implied Foreign Exchange Rates Using Options Prices.” International Review of Financial Analysis, 5, No. 3 (1996), pp. 171-183.

Britten-Jones, M., and A. Neuberger. "Option Prices, Implied Price Processes, and Stochastic Volatility." Journal of Finance, 1999, forthcoming.

Brown, G., and K. B. Toft. "Constructing Binomial Trees from Multiple Implied Probability Distributions." Journal of Derivatives 7, No. 2 (1999), forthcoming.

Buchen, P., and M. Kelly. “The Maximum Entropy Distribution of an Asset Inferred from Option Prices.” Journal of Financial and Quantitative Analysis, 31, No. 1 (1996), pp. 143-159.

Campa, J., and K. Chang. “Arbitrage Based Tests of Target Zone Credibility: Evidence from ERM Cross-Rate Options.” American Economic Review, 86 (1996), pp. 726-740.

Campa, J., and K. Chang. "ERM Realignment Risk and its Economic Determinants as Reflected in Cross-Rate Options.” Economic Journal, 108, No. 449 (1998), pp. 1046-1066.

Campa, J., K. Chang, and J. Refalo. “An Options-Based Analysis of Emerging Market Exchange Rate Expectations: Brazil’s Real Plan, 1994-1999.” Working Paper, New York University, 1999. Campa, J., K. Chang, and R. Reider. "Implied Exchange Rate Distributions: Evidence from OTC Option Markets.” Journal of International Money and Finance, 17, No. 1 (1998), pp.117-160.

Carr, P., and D. Madan. "Determining Volatility Surfaces and Option Values from an Implied Volatility Smile.” Working Paper, University of Maryland, 1998.

Chriss, N. "Transatlantic Trees.” RISK, 9 (1996), pp. 45-48.

Cochrane, J., and J. Saa-Requejo. "Beyond Arbitrage: Good-Deal Asset Price Bounds in Incomplete Markets.” Journal of Political Economy, 1999, forthcoming. 
Coleman, T., Y. Li, and A. Verma. "Reconstructing the Unknown Volatility Function." Working Paper, Computer Science Department, Cornell University, 1998.

Cont, R. "Beyond Implied Volatility." In Kertesz, J., and I. Kondor, ed, Econophysics. Dordrecht: Kluwer, 1997, forthcoming.

Coutant, S., E. Jondeau, and M. Rockinger. "Reading Interest Rate and Bond Futures Options' Smiles: How PIBOR and Notional Operators Appreciated the 1997 French Snap Election." Working Paper, HEC, 1998.

Corrado, C., and T. Su. "Skewness and Kurtosis in S\&P 500 Index Returns Implied by Option Prices." Journal of Financial Research, 19, No. 2 (1996), pp. 175-192.

Corrado, C., and T. Su. "Implied Volatility Skews and Stock Index Skewness and Kurtosis Implied by S\&P 500 Index Option Prices.” Journal of Derivatives, 4, No. 4 (1997), pp. 8-19.

Cox, J., S. Ross, and M. Rubinstein. "Option Pricing: A Simplified Approach.” Journal of Financial Economics, 7, No. 3 (1979), pp. 229-263.

Derman, E., and I. Kani. “Riding on a Smile.” Risk 7, No. 2 (1994), pp. 32-39.

Derman, E., and I. Kani. "Stochastic Implied Trees: Arbitrage Pricing with Stochastic Term and Strike Structure of Volatility." International Journal of Theoretical and Applied Finance, 1 (1998), pp. 7-22.

Derman, E., I. Kani, and N. Chriss. “Implied Trinomial Trees of the Volatility Smile.” Journal of Derivatives, 3, No. 4 (1996), pp. 7-22.

Dumas, B., J. Fleming, and R. Whaley. "Implied Volatility Functions: Empirical Tests.” Journal of Finance, 53, No. 6 (1998), pp. 2059-2106.

Dupire, B. "Pricing With a Smile.” Risk, 7, No. 1 (1994), pp. 18-20.

Hartvig, N., J. Jensen, and J. Pedersen. "Risk Neutral Densities of the 'Christmas Tree' Type." Working paper, Centre for Mathematical Physics and Stochastics, Aarhus University, 1999. 
Heath, D., R. Jarrow, and A. Morton. "Bond Pricing and the Term Structure of Interest Rates: A New Methodology for Contingent Claims Valuation.” Econometrica, 60, No. 1 (1992), pp. 77105.

Herrmann, R., and A. Narr. "Risk Neutrality.” RISK, 10, Technology Supplement (1997), pp. 2329.

Hutchinson, J., A. Lo, and T. Poggio. "A Nonparametric Approach to Pricing and Hedging Derivative Securities via Learning Networks.” Journal of Finance, 49, No. 3 (1994), pp. 851-889. Jackwerth, J. “Generalized Binomial Trees.” Journal of Derivatives, 5, No. 2 (1997), pp. 7-17. Jackwerth, J., "Recovering Risk Aversion from Option Prices and Realized Returns." Review of Financial Studies, 1999, forthcoming.

Jackwerth, J., and M. Rubinstein. "Recovering Probability Distributions from Option Prices." Journal of Finance, 51 (1996), pp. 1611-1631.

Jackwerth, J. and M. Rubinstein. "Recovering Stochastic Processes from Option Prices." Working Paper, University of Wisconsin, Madison, 1998.

Jarrow, R., and A. Rudd. “Approximate Valuation for Arbitrary Stochastic Processes." Journal of Financial Economics, 10, No. 3 (1982), pp. 347-369.

Johnson, N. "Systems of Frequency Curves Generated by Methods of Translation." Biometrika, 36 (1949), pp. 149-176.

Jondeau, E., and M. Rockinger. "Estimating Gram-Charlier Expansions under Positivity Constraints." Working Paper, HEC, 1998a.

Jondeau, E., and M. Rockinger. "Reading the Smile: The Message Conveyed by Methods Which Infer Risk Neutral Densities.” Working Paper, HEC, 1998 b.

Lagnado, R., and S. Osher. "Reconciling Differences.” RISK, 10, No. 4 (1997), pp. 79-83. 
Laurent, J., and D. Leisen. "Building a Consistent Pricing Model from Observed Option Prices." Working Paper, Hoover Institute, Stanford University, 1998.

Leahy, M., and C. Thomas. "The Sovereignty Option: The Quebec Referendum and Market Views on the Canadian Dollar.” Working Paper, Federal Reserve Board, Washington DC, 1996.

Ledoit, O., and P. Santa-Clara. "Relative Pricing of Options with Stochastic Volatility." Working paper, UCLA, 1998.

Longstaff, F. "Martingale Restriction Tests of Option Pricing Models." Working Paper, University of California, Los Angeles, 1990.

Longstaff, F. "Option Pricing and the Martingale Restriction." Review of Financial Studies, 8, No. 4 (1995), pp. 1091-1124.

Mccauley, R., and W. Melick. "Risk Reversal Risk.” RISK, 9, No. 11 (1996), pp. 54-57.

Malz, A. "Using Option Prices to Estimate Realignment Probabilities in the European Monetary System: The Case of Sterling-Mark." Journal of International Money and Finance, 15, No. 5 (1996), pp. 717-48.

Malz, A. "Estimating the Probability Distribution of the Future Exchange Rate from Option Prices.” Journal of Derivatives, 5, No. 2 (1997), pp. 18-36.

Masson, J., and S. Perrakis. “A Jumping Smile.” Working paper, University of Ottawa, 1997.

Mayhew, S. “On Estimating the Risk-Neutral Probability Distribution Implied by Option Prices.” Working Paper, Purdue University, 1995.

Melick, W., and C. Thomas. "Recovering an Asset's Implied PDF from Option Prices: An Application to Crude Oil During the Gulf Crisis." Journal of Financial and Quantitative Analysis, 32 (1997), pp. 91-115.

Mizrach, B. "Did Option Prices Predict the ERM Crisis?” Working Paper, Rutgers University, 1996. 
Osborne, M. "Brownian Motion in the Stock Market." Operations Research, 7 (1959), pp. 145173.

Posner, S., and M. Milevsky. "Valuing Exotic Options by Approximating the SPD with Higher Moments.” Journal of Financial Engineering, 7, No. 2 (1998), pp. 109-125.

Potters, M., R. Cont, and J. Bouchaud. "Financial Markets As Adaptive Systems.” Europhysics Letters, 41, No. 3 (1998), pp. 239-244.

Pritsker, M. "Nonparametric Density Estimation and Tests of Continuous Time Interest Rate Models.” Working Paper, Federal Reserve Board, Washington DC, 1997.

Ritchey, R. "Call Option Valuation for Discrete Normal Mixtures." Journal of Financial Research, 13, No. 4 (1990), pp. 285-295.

Rookley, C. "Fully Exploiting the Information Content of Intra Day Option Quotes: Applications in Option Pricing and Risk Mangement.” Working paper, University of Arizona, 1997.

Rosenberg, J. "Pricing Multivariate Contingent Claims Using Estimated Risk-Neutral Density Functions." Working Paper, Department of Economics, University of California, San Diego, 1996.

Rosenberg, J., and R. Engle. “Option Hedging Using Empirical Pricing Kernels.” Working Paper, New York University, 1997.

Ross, S. “Options and Efficiency.” Quarterly Journal of Economics, 90 (1976), pp. 75-89.

Rubinstein, M. "Nonparametric Tests of Alternative Option Pricing Models Using All Reported Trades and Quotes on the 30 Most Active CBOE Option Classes from August 23, 1976 Through August 31, 1978." Journal of Finance, 40, No. 2 (1985), pp. 455-480.

Rubinstein, M. “Implied Binomial Trees.” Journal of Finance, 49, No. 3 (1994), pp. 771-818.

Rubinstein, M. “Edgeworth Binomial Trees.” Journal of Derivatives, 5, No. 3 (1998), pp. 20-27. 
Samperi, D. "Implied Trees in Incomplete Markets." Working Paper, Courant Institute, New York University, 1996.

Sherrick, B., P. Garcia, and V. Tirupattur. "Recovering Probabilistic Information from Option Markets: Tests of Distributional Assumptions." Working Paper, University of Illinois at UrbanaChampaign, 1995.

Sherrick, B., S. Irwin, and D. Forster. "Option-Based Evidence of the Nonstationarity of Expected S\&P 500 Futures Price Distributions." Journal of Futures Markets, 12, No. 3 (1992), pp. 275-290.

Sherrick, B., S. Irwin, and D. Forster. "An Examination of Option-Implied S\&P 500 Futures Price Distributions.” Financial Review, 31, No. 3 (1996), pp. 667-694.

Shimko, D. "Bounds on Probability.” RISK, 6 (1993), pp. 33-37.

Söderlind, P., and L. Svensson. "New Techniques to Extract Market Expectations from Financial Instruments.” Working Paper, Stockholm School of Economics, 1996.

Stutzer, M. “A Simple Nonparametric Approach to Derivative Security Valuation.” Journal of Finance, 51 (1996), pp. 1633-1652.

Tompkins, R. "Implied Volatility Surfaces: Uncovering the Regularities for Options on Financial Futures.” Working Paper, Vienna University of Technology and Warwick University, 1998.

Toft, K. and B. Prucyk. "Options on Leveraged Equity: Theory and Empirical Tests." Journal of Finance, 52, No. 3 (1997), pp. 1151-1180. 


\section{EXHIBIT 1}

Stock Prices for the Standard Binomial Tree

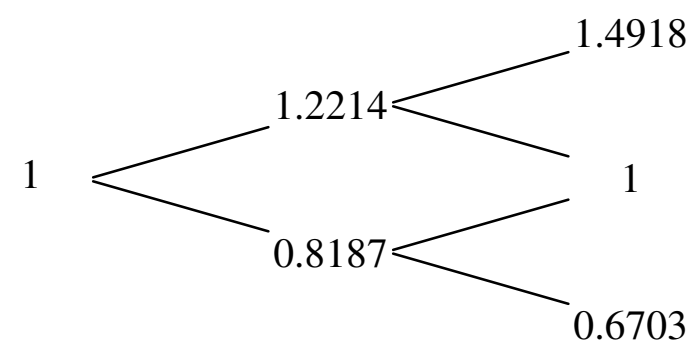




\section{EXHIBIT 2}

Probabilities for the Standard Binomial Tree

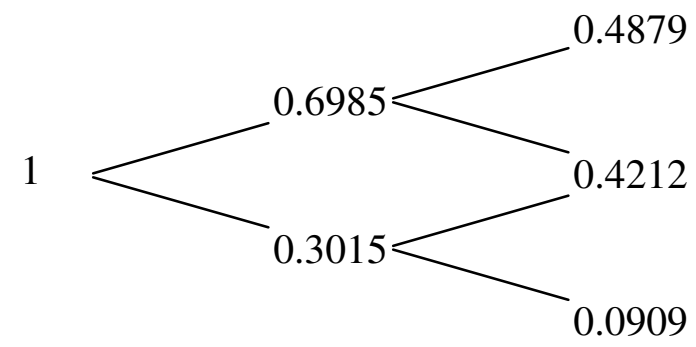




\section{EXHIBIT 3}

Stock Prices for the Implied Binomial Tree

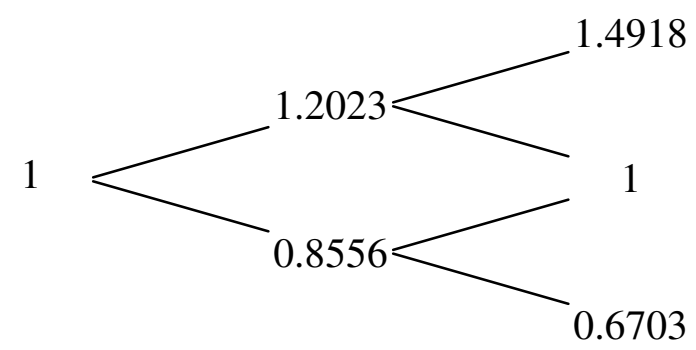




\section{EXHIBIT 4}

Probabilities for the Implied Binomial Tree

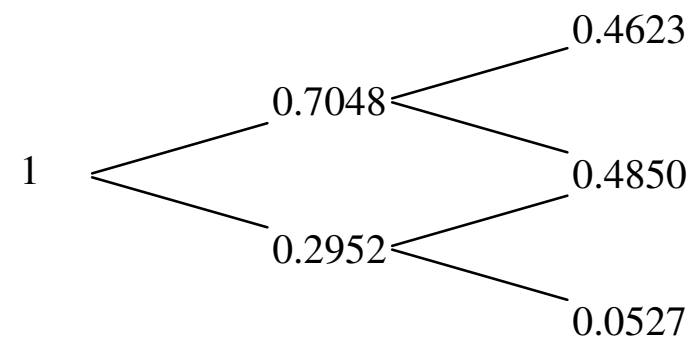




\section{EXHIBIT 5}

Stock Prices for the Generalized Binomial Tree

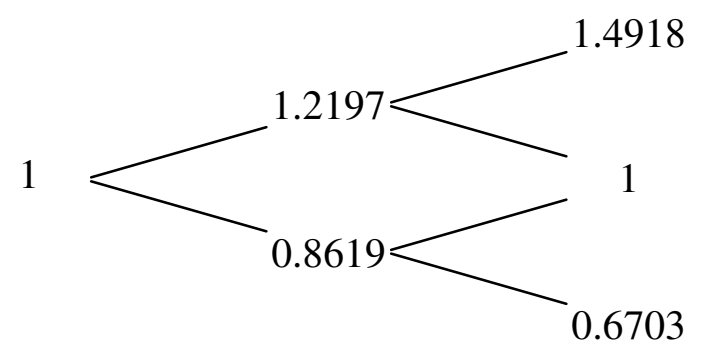




\section{EXHIBIT 6}

Probabilities for the Generalized Binomial Tree

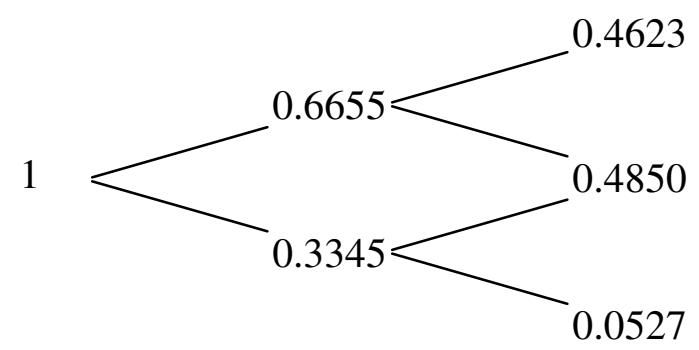




\section{EXHIBIT 7}

Stock Prices for the Derman and Kani Tree with Corrections by Barle and Cakici

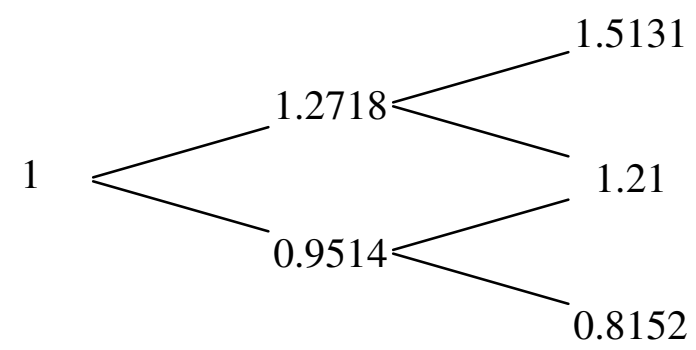




\section{EXHIBIT 8}

Probabilities for the Derman and Kani Tree with Corrections by Barle and Cakici

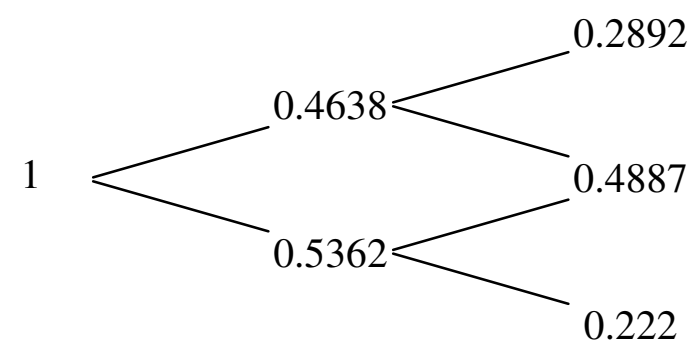

